\title{
MANUALES Y URBANIDAD: ANTECEDENTES PARA SU HISTORIA EN CHILE
}

\author{
Handbooks on Urbanity: Backgrounds for their History in Chile \\ Raquel Soaje de Elías ${ }^{1}$ \\ Manuel Salas Fernández²
}

\begin{abstract}
RESUMEN
¿Cómo se explica la necesidad constante del hombre de regular el comportamiento social, en las más diversas épocas, a pesar de haberse consolidado aparentemente el llamado "pacto social"? La respuesta supone diversas variables, pero constata un desafío permanente que la sociedad misma deberá enfrentar. A partir de esta interrogante, el presente trabajo se propone el estudio de los antecedentes de la urbanidad como paradigma de comportamiento social autocontrolado, y su evolución a través del tiempo, con el objeto de identificar sus rasgos fundamentales. En este contexto, intentaremos explicar cómo en el siglo XIX, con el resurgimiento de los ideales clásicos, se consideró su incorporación como contenido transversal en el currículum de instituciones escolares públicas y privadas de Chile, como elemento fundamental para "civilizar y moralizar" al joven ciudadano de la naciente república. De este modo, junto a la religión y a la moral, la urbanidad se constituiría en uno de los tres pilares fundamentales para consolidar el orden republicano, a partir de un proyecto orgánico de sociedad, difundido a través de la educación y basado en la autorregulación de la conducta, que el Estado liberal se propuso como meta, tanto en Chile como en el resto de América.
\end{abstract}

Palabras clave: Carreño, autocontrol, comportamiento social, civilizar, moralizar.

\begin{abstract}
How do you explain the constant need of man to regulate social behavior, in the most diverse periods of history, despite apparently having consolidated the so-called "social pact"? The answer involves several variables, but it shows a permanent challenge that society itself must face. Among them, this paper studies urbanity as a paradigm of self-controlled social behavior and its evolution over time in order to identify its fundamental features. In this context, we will explain how in the 19th century, with the resurgence of classical ideals, the incorporation of urbanity within the curriculum of public and private educational institutions in Chile, as a fundamental element to "civilize and moralize" the young citizens of the new republic . Thus, together with religion and morals, urbanity became one of three fundamental pillars to consolidate the republican order.
\end{abstract}

Key Words: Carreño, self-control, social behavior, civilize, moralize.

${ }^{1}$ Universidad de los Andes. Chile. Profesora de la Facultad Filosofía y Humanidades.
ID Orcid: https://orcid.org/0000-0003-0825-4454 / Correo electrónico: rsoaje@ @andes.cl.
${ }^{2}$ Universidad de los Andes. Chile. Profesor de la Facultad de Filosofía y Humanidades.
ID Orcid: https://orcid.org/0000-0003-2124-1455 / Correo electrónico: msalasf@ utexas.edu.

Recepción: 08/03/2019.

Aprobación: 09/07/2019. 


\section{Introducción}

El rector de una prestigiosa universidad chilena y columnista del principal diario local, El Mercurio, ha afirmado recientemente que "mientras las personas reclaman más libertad, y cada uno quiere tener la suya, más necesario se hace contar con reglas de tráfico que la regulen e inevitablemente la limiten” (Peña, 6 de mayo de 2018, p. 7). La afirmación, efectuada a propósito del acoso sexual que preocupa y moviliza a la población universitaria, cuestiona la misma posibilidad de libertad, y permite colocar sobre la mesa la cuestión de la autorregulación de la conducta como parte del proceso civilizatorio, que implica someterse voluntariamente con miras a disciplinar el propio comportamiento para mejorar así la convivencia social.

En este contexto, se enmarca el fenómeno que se analizará: la historia de la urbanidad en Chile. Este hito fue importante en la historia de la educación y coincidió con la necesidad de la burguesía de imitar los modos de comportamiento de las élites luego del furor revolucionario de fines del siglo XVIII (Soaje, 2015). Dicho fenómeno se vinculaba con los ideales de vida que, desde la Antigüedad, preocuparon a diversos poetas y filósofos, los cuales intentaron transmitirlos a través de sus obras, y de este modo influyeron en la formación de personajes, erigidos con el tiempo, en modelos de sus respectivas épocas.

Esta inquietud se mantuvo en el tiempo y se tradujo en un modo de regular la conducta, no solo en el ámbito moral, sino también a través de prácticas exteriores al sujeto, tanto domésticas como sociales, tales como las maneras de mesa, el modo de usar el vestido y la forma de llevar una conversación, cuya consecuencia desencadenó la publicación de múltiples textos destinados a difundir los buenos modales. En el Chile republicano de 
mediados del siglo XIX, adquirieron gran prestigio varios de estos textos referidos a la urbanidad, como manifestación de aquella inquietud; un ejemplo elocuente de ella fue el éxito del llamado "Manual de Carreño".

A fines del siglo XIX y principios del XX, se produjo una ruptura de los ideales de vida decimonónicos, ruptura que se consolidó en las décadas siguientes como consecuencia de acontecimientos traumáticos para Occidente, como fueron las dos guerras mundiales. Hacia mediados de dicha centuria, con la irrupción de los movimientos de protesta juveniles que cuestionaban el estilo de vida anterior a las guerras, se produjo la decadencia de las normas de urbanidad, que comenzaron a considerarse obsoletas, al desvincularse de una formación de carácter humanista, y oponerse al nuevo estilo de vida impuesto a partir de la posguerra. La educación en general, que había recibido a su vez la impronta del movimiento positivista y laico, y la influencia de los principios pedagógicos de la Escuela Nueva tendió a volverse más profesional y técnica durante el periodo mencionado, dejando de lado las humanidades, de la mano de las cuales se enseñaban las “buenas maneras". La reducción de los contenidos de las humanidades en los planes curriculares actuales es una muestra fehaciente de este fenómeno (Soaje de Elías, 2012b); en ellos, los denominados "valores democráticos" han reemplazado a los valores considerados "universales", que propiciaba la educación humanista y que estaban presentes aún en los textos de urbanidad decimonónicos.

En este contexto, la urbanidad en Chile ha sido analizada, hasta ahora, desde el ámbito filosófico o literario, poniendo énfasis en su nexo con los ideales éticos o estéticos de la época (Cataldo Sanguinetti, 2005), o bien desde la problemática de la formación de la juventud en la sociedad republicana, de acuerdo con el imaginario burgués (Toro Blanco, 2012). Por tanto, se necesita un análisis integral de la urbanidad, el cual, desde una perspectiva 
netamente histórica, logre integrar los aportes de las distintas disciplinas que lo han estudiado, situándolo en el contexto social y cultural que le es propio.

Además, la existencia de un tipo de educación humanística derivada de la tradición clásica plantea un desafío importante que obliga a indagar en los orígenes de uno de sus rasgos fundamentales: el autodisciplinamiento. Dicho rasgo, destinado a lograr el control de sí mismo como medio eficaz para una mejor convivencia social, era plenamente acorde a los principios republicanos que se intentaban reforzar a través de la educación, sobre todo a partir de la independencia, tanto en Chile como en el resto de las emergentes naciones hispanoamericanas. Desde un punto de vista teórico, la finalidad estética, y no solamente la ética, que se halla implícita en la urbanidad, plantea también la necesidad de definir sus elementos fundacionales para comprender la problemática de su incorporación en los postulados educativos decimonónicos.

De este modo, el presente trabajo se propone estudiar los antecedentes de la urbanidad en la cultura grecorromana y su nexo con la paideia y la humanitas clásicas, como paradigma de comportamiento social autocontrolado, analizando los conceptos subyacentes y concomitantes a esta problemática, y su evolución a través del tiempo, con el objeto de identificar sus rasgos fundamentales con sus respectivos cambios y continuidades. A partir de la definición de este marco conceptual y su correspondiente contexto histórico, se explicará cómo en el siglo XIX, con el resurgimiento de los ideales clásicos, se consideró la incorporación de la urbanidad como contenido transversal en el currículum de instituciones escolares públicas y privadas de Chile, como elemento fundamental para "civilizar y moralizar" al joven ciudadano de la naciente república (Monsalve y Egaña, 2006). 


\section{La urbanidad y sus antecedentes clásicos}

\section{a. Paideia y humanitas}

Para comprender cuáles eran los fundamentos teóricos de aquella formación clásica propia del siglo XIX que sirvió de sustento a las normas de urbanidad, se deben revisar sus principios.

Definida a grandes rasgos en oposición a la rusticidad, el término urbanidad urbanitas en latín- refirió desde sus orígenes a la cualidad propia de un hombre de costumbres refinadas, inserto en el ámbito urbano que, a través de sus modales considerados correctos, busca agradar a los demás y se distingue por ello del campesino, más sencillo y rústico en su actuar. Ya desde los tiempos de Homero, es posible registrar esta inquietud por los buenos modales y por el refinamiento propio de la mentalidad aristocrática. Este fenómeno se tradujo en un modo de regular la conducta, asociado a los requerimientos propios de la vida en comunidad, no solo en el ámbito moral, sino también a través de prácticas domésticas y sociales, tales como las maneras adecuadas en la mesa, el modo de usar el vestido y la forma de entablar una conversación. Su vinculación con una cultura de élite se desarrolló en el contexto de la civilización de la paideia clásica, la cual vio la aparición de obras escritas que resaltaban el estilo de vida considerado como ideal. Un ejemplo de ello es la Ciropedia de Jenofonte, reflejo de la preocupación de su autor por legar a la posteridad un modelo de gobernante educado, encarnado en la figura del rey persa: Ciro el Grande. En el libro I, cuando presenta el régimen alimenticio persa, comenta "que es vergonzoso entre ellos escupir, sonarse o no retener ventosidades en público, y es vergonzoso también dejarse ver yendo a algún lugar a orinar o a hacer cosas por el estilo" (Jenofonte, 
1987, p. 87 ). Más adelante, destaca la afabilidad de Ciro, su habilidad en las artes de la conversación y particularmente en el arte de agradar (Jenofonte, 1987, pp. 88-89).

En cuanto al vehículo de expresión de aquellas normas fueron, en términos generales, la poesía y otros géneros literarios, como los proverbios y, más precisamente, las sentencias; no obstante, es posible registrar también referencias a dichas normas en los filósofos griegos. Ya Aristóteles en su libro segundo de la Retórica (Aristóteles, 2000, pp. 275-282) definía una sentencia como aquel enunciado breve y conciso, referido a todas aquellas cosas generales que afectan a las conductas y que pueden elegirse o evitarse al actuar; esta definición evidencia los tres elementos esenciales de esta forma literaria: el valor general del contenido, su dimensión ética y su objetivo de regular el comportamiento moral y social del hombre, con un carácter eminentemente práctico (García Romero, 1999, pp. 9-11). Un referente importante en este sentido lo constituyen las Sentencias de Menandro, el principal representante de la comedia nueva, hacia finales del siglo IV y comienzos del III a. C. En este texto, juega un rol fundamental la educación como un bien inalienable (Menandro, 1999, p. 1), cuya posesión civiliza a los hombres (Menandro, 1999, p. 50) y cuyo premio es la virtud (Menandro, 1999, p. 120). No faltan en ellas referencias al vestido (Menandro, 1999, p. 135), a la comida y a la bebida, y también a la conversación; no obstante, el acento predominante está colocado más en lo moral que en las prácticas de urbanidad.

Dentro del mismo ámbito filosófico, una obra notable referida a los defectos que caracterizan a la gente mediocre y sin educación, la constituye aquella de los Caracteres de Teofrasto, discípulo de Aristóteles y sucesor suyo en la dirección del Liceo. Según observa Ruiz García (2007, pp. 21- 22), se trata de descripciones realizadas de manera ingeniosa, para completar lo expuesto por Aristóteles en la Ética a Nicómaco, probablemente con el fin de 
enseñar de forma entretenida. En esta obra, Aristóteles presentaba dos figuras contrapuestas, por exceso y por defecto, a aquella persona que destaca por su ingenio: el bufón y el rudo. Destinadas a provocar risa y, a la vez, reflexión, el objetivo final de las descripciones de Teofrasto se vincula con la obra de su maestro, y su objeto fue posiblemente la paideia, además de contribuir con el ideal filantrópico, antecedente griego de la humanitas romana. En este marco se inserta la descripción del rústico como persona ignorante de los modales propios de quien vive en la ciudad (Teofrasto, 2007, pp. 55-56). El término agroikos, relativo al hombre de campo, comenzó a utilizarse peyorativamente por influencia sofística hacia el fin del siglo V a. C., época que coincide con el desenlace de las guerras del Peloponeso, y que dio lugar a la noción de rusticidad recién mencionada. Otra descripción más detallada del prototipo del sujeto mal educado es la referida a la guarrería, cualidad que supone el desaliño y desaseo del cuerpo con la consiguiente repugnancia para los demás (Teofrasto, 2007, pp. 88-89). Son rasgos propios del guarro "sonarse mientras come, rascarse en medio de un sacrificio, salpicar con saliva cuando habla y eructar al tiempo que bebe, entre otros que causan asco y desagrado” (Teofrasto, 2007, pp. 88-89).

Según se resaltó anteriormente, aquel ideal filantrópico, producto de la educación, sería retomado, siglos más tarde, en el concepto romano de la humanitas, el cual, en último término, suponía la superioridad de los hombres sobre el resto de los vivientes. La filantropía universal fue la primera acepción de esta palabra; en segundo lugar, el concepto se relacionaba estrechamente con la cultura, y más precisamente con el conocimiento de los clásicos de la literatura grecorromana; una tercera acepción aludía al ideal estético y aristocrático de la vida que, según observa Quadrini, “en el uso corriente indica la virtud del hombre cortés, refinado, educado para nutrir sentimientos elevados; del hombre que en la 
sociedad lleva su carácter afable y amable, que es, en una palabra, un ser 'civilizado', 'urbano"” (1989, p. 166).

En el siglo I a. C., la idea de humanitas sería completada, principalmente, por Cicerón (Arbea, 2002), quien la describe finalmente como el ideal estético de un hombre virtuoso, que armoniza pensamiento y acción (Quadrini, 1989, p. 167). Humanitas, apunta Marrou (1985), es en definitiva la traducción que Cicerón y Varrón hicieron del término griego paideia, en su versión clásica y luego helenística, como así también su transmisión al mundo occidental, a través del aporte específico que realizaron los romanos. En este sentido, concluye el historiador francés:

Tendencia privativa del espíritu helenístico es hacer del hombre un valor supremo, entiéndase del hombre libre, rico y culto, a quien la educación ha transformado en hombre pleno, que ha llegado a la humanitas por el camino de la paideia (Marrou, 1985, p. 295).

\section{b. Cicerón y la urbanitas}

En las primeras décadas del siglo XX, la problemática del humanismo y la importancia de la enseñanza de las humanidades, volvió a manifestarse en el debate académico, cuando el cimbrón de la Primera Guerra Mundial movió los cimientos de la civilización occidental. En primer lugar, E. K. Rand, en 1932, escribía The Humanism of Cicero, y poco después, ante la inminente amenaza de una segunda guerra, su discípulo Georges P. Hayes reflexionaba también acerca del ideal de vida de su tiempo, afirmando que: 
En un día como el presente, cuando las mismas bases de nuestra civilización están siendo críticamente analizadas, cuando la vieja estructura de la sociedad está cediendo visiblemente en algunos lugares ..., se puede arrojar algo de luz sobre la situación si se decide primero cuál es nuestro objetivo en la reconstrucción de la sociedad (1939, p. 283).

En este contexto, el ideal de humanitas fue propuesto precisamente por Hayes como solución a la crisis de la cultura occidental, al ofrecer un tipo de hombre superior, el mismo que habían rescatado siglos antes: "San Jerónimo en el siglo IV, Bernardo de Chartres y John de Salisbury, en el XII, Petrarca y Poggio $^{3}$ Bembo $^{4}$ y Erasmo en el nuevo humanismo y en el Renacimiento" (Hayes, 1939, p. 283). En efecto, para el mismo Hayes, la humanitas de Cicerón se vinculaba al término civilitas, que definía como la cualidad que el ser humano adquiere en el proceso de desarrollo de lo mejor que hay en la naturaleza humana, un espejo de gentleman en contraste con el homo ferus, brutal o bestial que no posee cualidades sociales, tacto, cortesía, tolerancia hacia los demás, es decir, savoir faire. Por oposición al sentimentalismo del siglo XVII y al romanticismo del XIX, su propuesta suponía volver hacia esta forma superior de humanidad, y a través de la lucha moral y de la autodisciplina, aprender a ser "humano". Realmente notable es su consideración de que "ser humano no es un derecho de nacimiento" (Hayes, 1939, p. 284), y que el humanitarismo propio de su época, reducido a la compasión por el desvalido, no debe confundirse con el verdadero humanismo de Cicerón, forjado en el estudio y la autodisciplina, un concepto mucho más amplio que

\footnotetext{
${ }^{3}$ Gian Francesco Poggio Bracciolini (1380-1459), humanista italiano.

${ }^{4}$ Pietro Bembo (1480-1547), humanista italiano.
} 
engloba también aquella compasión, dirigida, no obstante, por la razón y no por el mero sentimiento, precisamente como resultado de la educación.

Un siglo después, estos conceptos eran aún objetos de preocupación y de estudio; Nancy Sherman, por ejemplo, dedicada al estudio de las maneras y su relación con la moral, retomaba el De Oficiis de Cicerón, para subrayar que este fue de lectura obligatoria para las clases cultas hasta el siglo XIX inclusive, por su visión del decoro, como reflejo del obrar virtuoso (Sherman, 2005, p. 273).

Esta cualidad propia de la humanitas, vinculada al refinamiento y la delicadeza en el trato social, es lo que en el mundo grecorromano se denominó urbanitas, concepto identificado en diversos pasajes de la obra de Cicerón, en tres sentidos diferentes, según observa Edwin Ramage en su estudio Early Roman Urbanity (1960). En primer lugar, aparece como sinónimo de refinamiento, en segundo término, como característica propia del ingenio humano que se denota en el hablar, y por último, como modo urbano de expresarse, el cual parece referir al tono de voz y a una cuidada pronunciación. No obstante, según este autor, ya existía conciencia de este fenómeno en las obras literarias latinas tempranas de los siglos III y II a. C. (Ramage, 1960, pp. 65-67).

En el caso específico de Cicerón, puede percibirse este triple sentido de un modo particular, en el De Officiis, dedicado a su hijo Marco, en el cual demuestra su preocupación por transmitirle, entre otros conocimientos, normas prácticas respecto al comportamiento adecuado en la sociedad romana de su época. Como base de todas ellas, se encuentra el concepto estoico del "dominio de sí", que implica, a su vez, el ejercicio de las virtudes fundamentales; entre ellas, sobresale la templanza (Cicerón, 1928, pp. 27-29), identificada 
por el romano como aquella parte de la honestidad que permite al hombre guardar una cierta medida y un cierto orden en todo cuanto en la vida se le ofrece, y a través de la cual guardará la honestidad y el decoro (Cicerón, 1928, pp. 11-13).

Por otra parte, es preciso remarcar la influencia que recibió Cicerón de la Ciropedia de Jenofonte. En este sentido, cabe notar que en el libro V de su obra acerca de la República, el retor retoma el perfil del príncipe encarnado en Ciro para aplicarlo a Escipión Africano, como modelo de gobernante romano, combinación perfecta entre máxima autoridad y afabilidad (Vegas Sansalvador, 1982, pp. 51-52). Ello demuestra una vez más que la humanitas, como concepto contrapuesto a la barbarie, constituía un elemento común entre griegos y romanos, integrador de la paideia y de la philanthropia (Inglebert, 2014, p. 20).

\section{c. Decorum y buenos modales}

Tanto la paideia como la humanitas se concibieron en el contexto de la ciudad. Según observa Inglebert, esta realidad era la que definía la identidad colectiva, encarnada en sus elementos esenciales, y que el autor rescata, a su vez, del tratado recientemente mencionado de Cicerón: foro, templos, pórtico, vías, leyes, derecho, tribunales, elecciones, costumbres. Realidad que constituía "un tema central y estructurante de las mentalidades antiguas" (Inglebert, 2014, p. 23), a la par que mostraba un estilo ideal de vida para quienes no vivían en ella.

Al mismo tiempo, en ese marco propio de la ciudad, la urbanidad puede comprenderse como manifestación visible de aquella civilización. Y dentro de ella resalta uno de sus rasgos fundamentales: el decoro. Definido como ornato de la vida en todo cuanto se dice o hace (Gómez Robledo, 1948, p. 21), el decorum se vincula con el término griego to prepon, que 
se relaciona a lo conveniente. Según observa Camarero, en su estudio titulado La teoría eticoestética del decoro en la antigüedad, los conceptos de prepon, decorum y afines se refieren a aquello que es debido al hombre, es decir, a su dignidad superior a todo lo creado, y son indicadores de lo bello en la época clásica (Camarero, 2000, p. 7). En griego, podrían traducirse por "distinguirse", "hacerse notar", lo cual se dirige principalmente a la persona en su aspecto exterior, vestimenta, arreglo, grata apariencia, prestancia física, o bien demuestra excelencia por su condición humana. Se usa en el sentido más preciso de ser adecuado, de buen gusto, elegante, de allí que se aplica también a la acción del hombre. Debe aclararse que no se refiere a conveniencia en el sentido de utilidad, deber moral, ventaja o necesidad, sino a lo que conviene al hombre según su naturaleza. Aplicado luego el concepto al obrar humano, comienza a identificarse con la belleza, definida como el esplendor de lo conveniente. Lo bello y lo bueno son dos manifestaciones de un mismo modo de actuar, y conforman una ética social e individual que obliga al hombre a comportarse de un modo agradable en relación con los demás. Así, el decoro manifiesta la excelencia de la naturaleza humana, realzando la gracia de la propia persona por su cultura y dignidad (Soaje, 2012a).

Por último, este concepto sobrevivió en el curso de los siglos como cualidad fundamental para identificar a la persona "decente", bien educada. Sirva como ejemplo la referencia de Lord Chesterfield al mismo Cicerón cuando menciona el término decoración como sinónimo de buena crianza, lustre de la urbanidad, la cual se adquiere gracias a la atención que se presta a la buena compañía, definida con sumo detalle, y al hábito de frecuentarla (Chesterfield, 1852, p. 336). ${ }^{5}$

\footnotetext{
${ }^{5}$ La presente carta está dirigida a su ahijado Stanhope y no señala fecha, aunque sí menciona el lugar, Bath.
} 


\section{Los buenos modales en la historia}

\section{a. El decoro en la Antigüedad tardía y el Medioevo}

La preocupación por los buenos modales pervivió en la época imperial romana, cuyo modo de vida austero, que había sido el ideal anterior a las grandes conquistas, quedó relegado completamente a ciertos círculos intelectuales de tendencia estoica, o bien con influencias neopitagóricas o cínicas, entre otras. La vida de la corte imperial y de las élites vinculadas a ella constituía el modelo a seguir y, en contraste con aquella austeridad, estos mantuvieron un alto nivel de lujo y ostentación de riquezas, aun en ámbitos cristianos, como en la Alejandría de las épocas antonina y severa.

Una muestra de ello puede percibirse en el tratado titulado El Pedagogo, cuyo autor, conocido precisamente como Clemente de Alejandría, tuvo a su cargo la escuela catequética de ese centro cultural y económico, a comienzos del siglo III. En aquella obra, Clemente rescata los principios fundamentales de la paideia griega como medio esencial para educar a sus alumnos, miembros de la élite culta de la ciudad, en las normas morales y sociales adecuadas para la práctica de la caridad evangélica. ${ }^{6}$ Nuevamente, se predica en ella la moderación como principio rector de las actividades de la vida cotidiana, junto a la cual destacan los buenos modales en el hablar, el vestir, el comer, entre otros. La identidad griega de Clemente y la incorporación, a la vez, del legado romano de las buenas costumbres de los antepasados, que los hijos de la Loba llamaron mores maiorum, queda al descubierto a través de las numerosas citas que recoge de los más variados autores griegos y romanos. Entre estos

\footnotetext{
${ }^{6}$ La obra mencionada ha sido objeto de múltiples estudios desde distintas perspectivas (Druille, 2013; Sanguinetti, 2000).
} 
últimos, se considera al alejandrino como deudor de Musonio Rufo, filósofo estoico del siglo I d. C. (Blázquez, 1994; Brown, 1987).

En la época tardorromana, surgieron nuevos tratados morales, que incluían normas de comportamiento social, resaltando la influencia de los preceptos legados por la Antigüedad. Uno de los más representativos es mencionado en las fuentes como Dísticos de Catón, y posiblemente fue escrito por un tal Dionisio Cato hacia el siglo IV d. C. (Cato y Chase, 1922).

Se intentó, de este modo, educar al ser humano, no solo atendiendo a la formación del intelecto, sino también de su voluntad a través de aquellas normas de comportamiento, moral y social. Al inicio de esta obra, rescatada en la modernidad por Erasmo y otros humanistas posteriores, se recuerda al joven lector los deberes para con Dios y con los mayores: rezar, honrar a los padres y parientes, temer al maestro, para entrar de lleno en recomendaciones sociales, tales como "saluda[r ] agradablemente, ... no te enojes sin causa, ... sé cuidadoso [con tus bienes]" (Erasmo y Arroyal, 1797, pp. 11-12.).

Esto pronto se vio reflejado, por ejemplo, en las reglas monásticas medievales, que fueron herramientas fundamentales para la transmisión de normas de conducta social en conventos, sobre todo considerando que muchos de los postulantes provenían de estratos sociales menos educados. El modo de vestirse, de alimentarse y de tratar a los demás, o bien las normas que atañen a la conversación, fueron considerados por estas reglas en los albores de la Edad Media, para ser transmitidos luego al mundo laico, ya avanzado el Medioevo (Soaje, 2014).

En la Baja Edad Media, y al inicio de la modernidad, los preceptos urbanos se fueron ampliando a distintos ámbitos a medida que se consolidaban las cortes de los diferentes reyes 
europeos. En este sentido, es notable el tratado de Andrés el capellán, que presenta el arquetipo de amante ideal en el siglo XIII, texto surgido en el entorno de la condesa María de Champaña, destinado a compilar las reglas de comportamiento adecuadas a las relaciones amorosas (Capellanus, 1960; cf. Capellán, 2006).

\section{b. El ideal de civilidad en la Edad Moderna}

En este mismo periodo, el autodisciplinamiento se exageró de tal modo en los medios cortesanos que dio lugar a un nuevo tipo de urbanidad, más afectada y sofisticada, propia del ambiente aristocrático e identificada como cortesía. ${ }^{7}$ El fenómeno descrito sirvió de base, en el siglo XX, al estudio pionero en la materia de Norbert Elias, abordado desde una perspectiva sociológica y psicológica.

Luego de enmarcar la civilidad dentro de las transformaciones sociales y políticas producidas en los inicios de la modernidad, las cuales sentaron las bases de la civilización occidental tal y como se desarrolló hasta el siglo XIX y comienzos del XX, el autor se cuestionaba allá por la década de 1930 por qué se produjo una ruptura en el proceso civilizatorio occidental (Elías, 1997). El énfasis puesto en el periodo moderno se relacionaba con el influjo y la difusión ejercida por la obra de Erasmo, De civilitate morum puerilium, la cual marcó un hito decisivo en el desarrollo de la conciencia de la civilidad, y en la conformación de las características propias de la civilización occidental (Erasmo, 2006). Este autor recogía en dicha obra diversos preceptos sobre el modo de comportamiento que deberían adoptar las personas en sociedad, en particular del externum corporis decorum para alcanzar lo que él denominó precisamente “civilidad”. Norbert Elias se ocupó expresamente

\footnotetext{
${ }^{7}$ Respecto del concepto y su tratamiento historiográfico, cf. Laspalas (1998) y Burke (1998).
} 
de este texto, en su intento de demostrar cómo los usos y las costumbres que se aceptaban en su época como naturales, eran, en realidad, el resultado de un largo proceso de aprendizaje del autocontrol. Dicho autor tomó esta obra como expresión de ruptura respecto de la tradición medieval, inaugurando la concepción más moderna del buen vivir, puesta de manifiesto, en parte, a través de la sustitución de ciertos términos fundamentales.

En efecto, Erasmo reemplaza el término civitas por civilitas, el cual, según Elias, le serviría a la sociedad europea para definirse a sí misma como civilizada; en este sentido, las buenas maneras constituyen el sello distintivo de la civilidad de las nuevas élites, encargadas de difundir los buenos modales. Cabe destacar que es Erasmo quien incorpora este nuevo concepto de civilitas, no referido ya necesariamente al orden y gobierno de una ciudad, sino más bien al modo como todo hombre educado debe comportarse en sociedad. Esto responde quizá al avance de un individualismo que se fue imponiendo, a medida que entró en decadencia el orden político y social medieval.

De civilitate morum puerilium es un breve manual dedicado al niño Enrique de Borgoña, hijo de Adolfo, príncipe de Veere, redactado en Friburgo en 1530. Según su autor, involucra varios objetivos. En primer lugar, que el niño desde pequeño aprenda a ser piadoso; en segundo lugar, que ame y se instruya de las enseñanzas liberales; en tercer lugar, que tome conocimiento de los deberes y oficios de la vida; y por último, que se acostumbre a la urbanidad en las maneras, aspecto en el cual centrará su atención (cf. Soaje, 2015). La obra está estructurada atendiendo primero a las reglas de comportamiento que se relacionan con el cuerpo, su aseo, sus movimientos, su presentación exterior, entre otros aspectos. En segundo lugar, se atiende a la vestimenta, como expresión de la traza del espíritu (Erasmo, 2006, p. xii); la regla fundamental que debe regirla es la honestidad, y su utilidad se asienta 
en cubrir aquello que es impudor mostrar a los demás. En tercer término, la atención se focaliza en la mesa y entra también en este ámbito el tema de la conversación (Erasmo, 2006, p. xvii). Este aspecto es tratado nuevamente en el apartado "De los encuentros" en el cual se detallan desde aspectos formales del modo de hablar y gestos hasta aquellos relacionados con el contenido mismo, respecto del cual destaca el ejercicio virtuoso que esta supone: no ensalzarse a sí mismo, no vituperar o hacer comentarios obscenos, no injuriar, etc. (Erasmo, 2006, p. xviii). Finaliza el tratado de Erasmo con indicaciones acerca de los juegos apropiados para los niños de bien y sus reglas, y así como el día acaba en el dormitorio, el apartado final lo dedica a ello (Erasmo, 2006, p. xix).

Por su parte, el epílogo refuerza el objetivo inicial de la obra, dedicada a Enrique, como exponente de los niños del mundo, para que se granjeen el ánimo de sus camaradas y para que les hagan estimables los estudios liberales y los referidos a las buenas maneras (Erasmo, 2006, p. xx). Los antecedentes de este tratado se ubican en obras de cortesía bajomedieval, las cuales surgen en las cortes a medida que se gestan y consolidan importantes cambios económicos y sociales, que afectan el modo de vida, el comportamiento en sociedad y las relaciones humanas. Entre ellos, están el renacimiento urbano y el surgimiento de los grupos sociales burgueses, ligados al auge del comercio y de la producción manufacturera, así como el resurgir del derecho romano, y con él un incipiente afán sistematizador y codificador que hará eclosión en épocas posteriores. De hecho, la obra de Erasmo resume en el fondo un código de normas de moralidad y sociabilidad, atesorado especialmente por el sector aristocrático de su época, el cual se identifica como el depositario de la virtud. En este sentido, Erasmo hace hincapié en la importancia del decoro exterior del cuerpo como 
expresión de la compostura interior del alma, lo cual conviene a todos, pero en especial a los niños y sobre todo a los de noble cuna (Erasmo, 2006, p. xx).

El caso de la obra erasmiana es un síntoma de cómo, con el redescubrimiento de la Antigüedad propiciada por los humanistas, se tuvieron en cuenta reglas de conducta que vinculaban lo ético y lo estético, como parte del fenómeno civilizatorio registrado con propiedad por Norbert Elias; de hecho, este autor reconoce los antecedentes antiguos del fenómeno de la urbanidad, aunque no se dedica a profundizar en ellos (Elías, 1997, p. 138). Para el mencionado Elias, el fenómeno de la civilidad se traduce en un proceso de cambio que transforma la coacción externa entre los seres humanos, en una autocoacción individual, el cual se agudiza a partir de la Baja Edad Media y del Renacimiento (Elías, 1997, p. 41). Se trata de un proceso que corre paralelo al resurgimiento del individuo, como bien lo identifica Georges Duby en el periodo que va entre los siglos XI a XIII, y que avanza en los siguientes hacia la conquista de su intimidad, para culminar en la distinción entre lo privado y lo público, distinción débil en los anteriores siglos medievales.

La veta abierta por Elias ha dado lugar a diversos trabajos por parte de historiadores como Roger Chartier, los cuales han realizado aportes significativos en este ámbito. Estos estudiosos, en el contexto de la historia de la vida privada, y de la historia de la lectura, han rescatado la civilidad como una forma de representación social, a través de la cual es posible comprender determinados tipos de sociedad, como la burguesa, la medieval y la del Antiguo Régimen (Laspalas, 1998, pp. 200-202; cf. Chartier, 1993).

A partir de estos estudios, al cual se debe añadir el de Jacques Revel acerca de los usos de la civilidad, inserto también en el marco de la historia de la vida privada, se produce 
una interdisciplinariedad en el abordaje de la civilidad, desde diversas perspectivas, entre las cuales, la sociológica posee una influencia dominante sobre las demás. En este contexto, la explicación del fenómeno gira entorno a la línea iniciada por Elias, lo cual se puede percibir en expresiones como la del mismo Revel, cuando afirma que dicho autor enmarcó, en definitiva, dentro de un mismo proceso civilizatorio, las transformaciones de la sociedad y de los comportamientos, destacando cómo "la imposición colectiva [de las normas] se convierte de este modo en objeto de gestión personal y privada" (1989, p. 170).

En el mismo sentido, se inscribe el estudio de Michael Foucault, en su obra sobre las Tecnologías del yo, acerca de "la historia del modo en que un individuo actúa sobre sí mismo", remontándose para ello a la Antigüedad. ${ }^{8}$ Este autor indaga acerca de la imposición de la disciplina al cuerpo, con el objeto de hacerlo dócil; se trata, según sus observaciones,

de trabajarlo en sus partes, de ejercer sobre él una coerción débil .... A estos métodos que permiten el control minucioso de las operaciones del cuerpo, que garantizan la sujeción constante de sus fuerzas, y les imponen una relación de docilidad-utilidad, es a lo que se puede llamar disciplinas (Foucault, 2003, pp. 140-141).

En definitiva, el fenómeno del autocontrol resurgió en los albores de la modernidad, a partir de las transformaciones socioeconómicas anteriormente mencionadas y bajo el influjo de los movimientos culturales del humanismo y el Renacimiento. De este modo, los ideales de vida de la Antigüedad fueron redescubiertos y asumidos en el proceso de formación de una sociedad “civilizada" y disciplinada, acorde con el establecimiento y la

\footnotetext{
${ }^{8}$ Cabe notar en este sentido la deuda contraída por Foucault con el filósofo Pierre Hadot, quien inspiró algunas ideas fundamentales de esta última obra, a través de su estudio Ejercicios espirituales y filosofía antigua (2006, p. 11).
} 
consolidación de los Estados modernos. En este contexto, la urbanidad se convirtió en uno de los rasgos distintivos de las élites aristocráticas durante la modernidad, exagerándose los códigos sociales de los ambientes cortesanos, al punto de provocar una reacción de aversión hacia ella entre quienes no gozaban del mismo estatus sociopolítico. El momento culminante de esta eclosión coincidió con el desenlace revolucionario contra el denominado Antiguo Régimen, en la Francia de 1789. De acuerdo con ello, se analiza el influjo de la Revolución francesa en el fenómeno que ocupa a este artículo.

\section{c. La Revolución francesa y el savoir vivre}

Frédéric Rouvillois ha definido la cortesía como un "cierto tipo de comportamiento" que se basa, por una parte, en principios morales universales e inmutables, y por otra, en usos definidos en función de las estructuras sociales, políticas, económicas, religiosas o ideológicas que rigen un lugar en una época determinada (Rouvillois, 2008, p. 13). El mismo tipo de comportamiento remite, a su vez, a un “conjunto más o menos coherente de las reglas de urbanidad y de las sanciones que las acompañan”, cuya finalidad apunta a

asegurar cierto número de funciones sociales precisas: integración (en el grupo donde está en vigor); distinción (en relación con los otros grupos o con quienes no pertenecen al grupo; regulación (de los comportamientos en el grupo, con el fin de prevenir o resolver los conflictos) (Rouvillois, 2008, p. 20).

También observa dicho autor, que en el marco de la Revolución francesa, se produjo en Francia un cuestionamiento del modo de vida propio de los grupos nobiliarios vinculados al poder monárquico, que tenía su fundamento en el pensamiento de Voltaire o de Rousseau, y a partir del cual los revolucionarios consideraron a la cortesía como "un medio criminal y 
disimulado para distinguirse, para colocarse por encima de los otros y, de paso, humillarlos rebajándolos” (Rouvillois, 2008, p. 25). Este cuestionamiento tenía su razón de ser en el predominio de la corte de Luis XIV y de sus sucesores, como “centro de gravedad de la alta sociedad, de la vida mundana y de los buenos modales” (Rouvillois, 2008, p. 57). Un tratado propio de la época revolucionaria, escrito por Louis-Marin Henriquez que data del tercer año de la república, presenta un ejemplo claro de esta actitud crítica hacia la cortesía del Antiguo Régimen, identificada como expresión de una moral de las bellas apariencias. Este autor define la civilidad como

una virtud que establece entre los hombres un trato amable y honesto, que prevalece de manera cortés, sin falsedad, sin afectación. Ella no solo compone el exterior del ciudadano sino que guía su alma y lo convierte en un ser social (Henriquez y Hugand, 1795, pp. 7-8).

Y más adelante, concluye que la civilidad exige el aseo en la persona y en su vestimenta, aunque no el excesivo adorno que quita mucho tiempo y hace que el hombre, y sobre todo la mujer, no piense más que en sí mismo (Henriquez y Hugand, 1795, p. 13).

Cabe mencionar que hasta ese momento el código del savoir vivre, expresión francesa para definir los buenos modales, había sido practicado por las distintas generaciones de familias aristocráticas a causa de la transmisión oral. Se trataba de un código social más refinado, dirigido a las élites, que tenía su modelo en la obra de Castiglione, El Cortesano (Paternoster, 2004). Este código de comportamiento dependía de un tipo de enseñanza gestada desde muy temprana edad, en el ámbito doméstico, que apelaba a métodos de corrección permanente, donde el ejemplo y la imitación de los mayores jugaba un rol 
primordial, rememorando, a su vez, el estilo de la paideia griega, guiada por la búsqueda de la excelencia, en este caso, social.

No obstante, pasado el furor revolucionario, hacia el 1800, se produjo un cambio profundo en el papel social de la cortesía, dando lugar a la aparición de numerosos manuales para regularla. Según la opinión de Rouvillois, el motivo de esa reaparición fue la consolidación de la burguesía, debido a que esta se apropió de los antiguos usos como señal de reconocimiento y distinción. De allí que el siglo XIX fuera el siglo de oro de la cortesía, no solo en Francia, sino también en otros países como Gran Bretaña o Estados Unidos (2008, p. 58).

En el ámbito inglés, por ejemplo, el término politeness tuvo su fundamento en un conjunto de valores que expresó la fe en el altruismo humano, propia del siglo XVIII, una vez que se hubo liberado de las “creencias irracionales", por la luz de la "razón”. Ello se manifestaba de un modo superficial en un código de regulación de la conducta, desde el modo de hacer una reverencia y saludar hasta la manera apropiada de sostener una taza de té. Pero según observa Paul Langford, de un modo más profundo, ese código se tradujo en manners en Inglaterra, o moeurs en Francia, admiradas por los extranjeros como reflejo de su cultura civilizada (Langford, 1997, p. 55). Thomas Macdonald, por ejemplo, consideraba que el modelo de la moderna civilidad propia del gentleman inglés era el resultado de la combinación de un temperamento y bien ordenada libertad, de la independencia de la persona y la igualdad de derechos (Langford, 1997, p. 56). Sin embargo, un siglo después, dicho gentleman sería visto como supervivencia de la influencia aristocrática más que como reflejo de un código social igualitario (Langford, 1997, p. 71). Su frialdad y falsa apariencia serían un obstáculo para la democratización de las maneras en la sociedad occidental. 
El siglo XIX, que ya había vivido la Revolución francesa en el continente, traería nuevos aires acerca de las buenas maneras, ligadas ahora a los ritos de la vida burguesa. Una muestra de ellos fue el texto de Madame Celnart, titulado Nouveau manuel complet de la bonne compagnie, ou guide de la politesse et de la bienséance (Bayle-Movillard, 1839), que invitaba a civilizar el interior doméstico a la hora de realizar prácticas cotidianas. Así, en esta etapa posrevolucionaria, se refiere a un nuevo savoir vivre, más flexible y moderado, "una herencia interpretada y reapropiada por élites sociales cada vez más diseminadas y homogéneas", adaptado al propio discurso de la nueva burguesía, que necesitaba rescatar los buenos modales como signo de distinción y reconocimiento (Rouvillois, 2008, pp. 5-8). Por otra parte, la movilidad social que permite el progreso de la clase media impulsa, a su vez, el género literario de los manuales de urbanidad y buenas maneras, que se multiplican por doquier (Rouvillois, 2008, pp. 58-59). Además, esta proliferación se conjugó con un renovado interés por el Tratado de los Deberes de Cicerón; aunque también la producción de esta literatura se unió a otro fenómeno, vinculado a la codificación escrita del derecho. Esta, bajo el influjo positivista, buscaba regular todos los aspectos de la vida cívica y pública, a través de normas impresas en los diferentes códigos: civil, comercial y penal. En consonancia con esta práctica, los textos de urbanidad decimonónicos se proponían también reglamentar todo lo referente al espacio privado (Rouvillois, 2008, p. 60).

Este fenómeno trajo consigo una nueva rigidez respecto de los usos y las costumbres sociales, afectando de modo particular la concepción acerca del cuerpo, considerado el resultado de una construcción, cuyos movimientos estaban regidos por un conjunto de reglas, de complejos rituales de interacción, posturas y actitudes inducidas, entre otros aspectos (Corbin, 2005, pp. 15-22). La reacción ante este encorsetamiento no tardaría en llegar de la 
mano de las nuevas ideas que desembocarían en la Gran Guerra, y desestabilizarían este edificio social y cultural burgués, que demostraría su condición inestable. ${ }^{9}$

\section{d. América entre la Ilustración del siglo XVIII y el liberalismo del siglo XIX}

Lo sucedido en la Francia revolucionaria que diseminó sus ideas en todo el occidente europeo tuvo su tinte peculiar en el Imperio español y sus reinos de ultramar. La monarquía hispánica se vio renovada por el espíritu ilustrado con la llegada de los borbones franceses al trono español. Asimismo, esta particularidad influenció el proceso de asimilación de aquellas ideas ilustradas en la América española, las cuales alcanzaron su momento culminante durante el reinado de Carlos III. Su ideal de gobierno referido a la "felicidad del pueblo" imprimió un sello distintivo a su reinado, cuya preocupación central fue rotando desde el ejercicio de la justicia, en tanto acción primordial del acto de "regir", dando y protegiendo a cada uno en lo suyo, para volverse cada vez más hacia la política, en un sentido moderno, vinculado más específicamente a la administración del Estado. Así, se asumió un "giro reformador", que tendió "a imponer desde arriba los ideales ilustrados, a difundir las luces esto es, los conocimientos y la moralidad-y a fomentar la prosperidad pública" (Bravo Lira, 1992, p. 24).

En el caso específico americano, estas ideas, se tradujeron en un intento de ordenar la administración de las posesiones allende el Atlántico, con lo cual la reglamentación invadió los ámbitos de la esfera pública, apareciendo una nueva forma de responsabilidad del individuo, no ya ante la justicia, sino ante la administración (Bravo Lira, 1992, pp. 42-43).

\footnotetext{
${ }^{9}$ Respecto de esta problemática existen varios trabajos referidos al proceso de des-civilización (e.g., Ampudia, 2008; Chartier, 2015).
} 
En este contexto, es oportuno acotar como ejemplo que el rigor y el aumento de la penalidad para enfrentar la "contaminación moral", en palabras de Armando de Ramón, fue considerado como instrumento para solucionar dicho problema (2011, p. 112).

Sin embargo, todavía no se vislumbra, en el ámbito sociopolítico, un impulso revolucionario, sino más bien un movimiento descendente de la acción de las élites cultas hispanoamericanas, intentando influir en el modo de vida del pueblo, en pos de alcanzar su felicidad. En Chile, es posible percibir dicha preocupación por señalar el modo de comportamiento dentro del ámbito privado, a través de documentos más bien epistolares; entre ellos, se pueden mencionar la carta de Manuel Riesco a su "amado hijo Miguel" de 1805 (Riesco, 1969), empresario peninsular emigrado a tierras chilenas y emparentado con una antigua familia fundadora por su matrimonio. Sus consejos forman parte de los códigos de moralidad vigentes en la sociedad europea de la segunda mitad del siglo XVIII, y constituyen una especie de manual de moralidad que señala, en palabras de Villalobos, “el ethos del quehacer mercantil” (2006, p. 26). No se publicó en su época, debido al carácter privado del documento, pero el historiador Villalobos ha reseñado y comentado sus consejos, entre los que destacan, en primer lugar, los de carácter religioso: practicar el santo temor de Dios, encomendarse a Él antes de iniciar sus negocios, rezar las oraciones de la mañana, el rosario y las oraciones de la noche, entre otros; luego, se ocupa de aspectos vinculados al decoro: apartarse de las malas compañías, de los juegos y de los espectáculos profanos, evitar la visita a personas del bello sexo, que siempre son "motivo de escollos", recogerse temprano, comportarse con humildad, cortesía y guardando la compostura, usar vestimenta sencilla, ser fiel en los negocios y prudente en los tratos concertados, no engañar a sus clientes, entre varios más de naturaleza práctica (Villalobos, 2006, pp. 26-30). En todo el documento, queda 
de manifiesto la conjunción entre las categorías éticas tradicionales y las nuevas modalidades del comercio (Villalobos, 2006, p. 31).

En consonancia con los consejos de Riesco, es posible citar también un documento del mismo estilo epistolar, dirigido a sus hijos, escrito por un personaje de trascendencia en el ámbito político de los inicios de la vida independiente: don Manuel de Salas. La carta, fechada en 1822, señala también la preocupación de los hombres de la Independencia por legar a su descendencia consejos de moralidad y buena crianza para conducirse en sociedad (Salas, 1910, pp. 216-218). En este mismo sentido, la actitud de otro personaje notable del mundo hispanoamericano, Simón Bolívar, es una muestra de que dicha preocupación era común a su época. Su carta, escrita desde Lima en 1825, enviada al maestro de su sobrino Fernando con instrucciones precisas acerca de cómo guiar a su pupilo, da cuenta del pensamiento del prócer americano y de la importancia que le asigna a la educación "como quien sabía que sin costumbres nada valen las leyes, y que sin rectitud y sin justicia no hay sino miserias y ruina" (Larrazábal, 1890, pp. xv-Xvi).

Mientras las fuentes recién citadas utilizaban un modo epistolar que da cuenta de su intención de aconsejar desde el fuero doméstico y familiar, acerca del modo de comportarse apropiado a un hombre de mundo, a través de un tono de sugerencia, la constitución moralista de Juan Egaña expone la nueva tendencia a plasmar esas sugerencias en un código de conducta. Este documento tenía, entre sus objetivos principales, inculcar la moralidad en los ciudadanos transformándola en ley para la acción (Silva Vargas, 2013, p. 568), a la vez que intentaba imponer rígidamente el perfil ideal del nuevo ciudadano republicano. Formado intelectualmente también en Lima, Juan Egaña fue "un destacadísimo representante del utopismo iluminista, alimentado por la antigüedad clásica, que imperó entre los americanos 
más instruidos de la época de la emancipación y, como tal, la constitución de 1823 no hizo sino reflejar su sistema de pensamiento" (Silva Vargas, 2013, pp. 567-568; cf. Góngora, 1980).

Dentro de este contexto de orden y moralidad, estructurado por las ideas ilustradas, y a pesar del fracaso de la constitución "moralista", la preocupación por la felicidad y las buenas costumbres del pueblo mantiene su vigencia tanto para el nuevo Estado como para algunos particulares. Esto se percibe en la tímida aparición de textos de buena crianza y manuales de urbanidad que se editan ya en la primera mitad del siglo XIX como parte de la bibliografía escolar de colegios privados, y que se multiplican hacia mediados de dicha centuria, cuando se produce la expansión de las escuelas públicas. Dichos textos tienen la peculiaridad de ser escritos con la intención expresa de inculcar aquellas normas de comportamiento, desde la niñez a través de la educación formal y no formal. Se trata de una inquietud generalizada a nivel americano, tanto en el ámbito público como privado.

Uno de los manuales más difundidos durante el periodo que ocupa este análisis fue el del español José de Urcullu. De origen comerciante, este vasco polifacético emigrado por razones políticas a Londres, tuvo la buena fortuna de trabajar como traductor para la casa británica Ackermann, afamada por su inmersión en el negocio de libros hispanoamericano. En la segunda mitad del siglo XIX, pueden contarse al menos treinta y tres publicaciones de su obra Lecciones de moral y urbanidad, cuya primera edición data entre 1825 y 1826 en Londres, realizada precisamente por el mismo Rudolph Ackermann (Roldán Vera, 2003, pp. 258-259). Además de la difusión del texto de Urcullu, el venezolano Manuel Antonio Carreño también publicó su propio manual que debió competir con muchas otras publicaciones en las jóvenes naciones americanas. En el caso de Chile, el compendio de este 
manual fue impreso en la década de 1860 por la Imprenta El Mercurio de Valparaíso (Carreño, 1863), y gozó de amplia difusión durante el siglo XX, e incluso en el XXI. Cabe acotar que en el último año, el manual en su versión completa ha sido publicado por Zig Zag, una adaptación de la editorial a los tiempos posmodernos (Carreño, 2018).

\section{Conclusión}

En definitiva, las reflexiones del rector Peña confirman la necesidad de las normas de sociabilidad: "Mientras las personas reclaman más libertad, y cada uno quiere tener la suya, más necesario se hace contar con reglas de tráfico que la regulen e inevitablemente la limiten" (Peña, 2018, p. 7). Este análisis implica considerar que la aparente dicotomía entre libertad y regulación del comportamiento puede ser resuelta rescatando la afirmación de Hanna Arendt acerca del caso Eichman (Arendt, 2014): "El acto moral siempre es libre”, y aunque el marco de moralidad sea impuesto, el ser humano puede actuar según su voluntad, tal como lo demuestran innumerables ejemplos en la historia. ¿Por qué se explica sino la necesidad constante del hombre de regular el comportamiento, en las más diversas épocas, a pesar de haberse consolidado aparentemente el llamado "pacto social"? La respuesta supone diversas variables, pero constata un desafío permanente que la comunidad misma deberá enfrentar, dados los eventuales alcances coercitivos y el posible efecto de control propio de las estrategias de regulación de la conducta, a las cuales se ha aludido anteriormente.

En el caso de la cosmovisión del siglo XIX, junto a la religión y a la moral, la urbanidad se constituiría en uno de los tres pilares fundamentales para consolidar el orden republicano, a partir de un proyecto orgánico de sociedad, difundido a través de la educación 
y basado en la autorregulación de la conducta, que el Estado liberal se propuso como meta, tanto en Chile como en el resto de América.

\section{Referencias bibliográficas}

Ampudia, H.F. (2008). La duda de Norbert Elías: Ampliaciones en la teoría del proceso civilizatorio. Política y sociedad (Madrid), 45(3), 177-197.

Arbea, A. (2002). El concepto de Humanitas en el Pro Archia de Cicerón. Onomázein, (7), 393-400. Recuperado de http://onomazein.letras.uc.cl/Articulos/7/18_Arbea.pdf

Arendt, H. (2014). Eichmann en Jerusalén. Santiago, Chile: Penguin House.

Aristóteles. (2000). Retórica. Barcelona, España: Gredos.

Bayle-Movillard (Élisabeth Celnart), E.F. (1839). Nouveau manuel complet de la bonne compagnie ou Guide de la politesse et de la bienséance: Dédié à la societé Française et à la jeunesse des deux sexes. Paris, Francia: Roret.

Blázquez, J.M. (1994). El empleo de la literatura greco-romana en el Pedagogo (LII) de Clemente de Alejandría. Gerión, (12), 113-132. Recuperado de http://revistas.ucm.es/index.php/geri/article/download/geri9494110113a/14489

Bravo Lira, B. (1992). El absolutismo ilustrado en Hispanoamérica: Chile (1760-1860) de Carlos III a Portales y Montt. Santiago: Universitaria.

Brown, P. (1987). La antigüedad tardía. En P. Brown y otros (Eds.), Historia de la vida privada. Vol. 1: Del Imperio romano al año mil (pp. 229-304). Madrid, España: Taurus. 
Burke, P. (1998). Los avatares de 'El Cortesano': lecturas e interpretaciones de uno de los libros más influyentes del Renacimiento. Barcelona, España: Gedisa.

Camarero, A. (2000). La teoría eticoestética del decoro en la antigüedad. Bahía Blanca, Argentina: Ediuns.

Capellán, A. (2006). El libro del amor cortés. Madrid, España: Alianza.

Capellanus, A. (1960). The art of courtly love. New York, USA: Columbia University Press.

Carreño, M.A. (1863). Manual de Carreño. Valparaíso, Chile: Zig-Zag.

Carreño, M.A. (2018). Manual de Carreño. Edición revisada y actualizada por Andrea Viu. Santiago: Zig-Zag.

Cataldo Sanguinetti, G. (2005). Las buenas maneras o la moral de las apariencias. Revista de Humanidades, (10), 7-19. Recuperado de http://repositorio.unab.cl/xmlui/bitstream/handle/ria/2183/Cataldo_Las\%20buenas\% 20maneras\%20o\%20la\%20moral\%20de\%20las\%20apariencias_2005.pdf?sequence $=1$

Cato, D. y Chase, W. J. (1922). The Distichs of Cato: A Famous Medieval Textbook. Madison, WI: University of Wisconsin.

Chartier, R. (1993). Libros, lecturas y lectores en la Edad Moderna. Madrid, España: Alianza. 
Chartier, R. (2015). Civilización y urbanidad, barbarie y decivilización. Pensar con Elías. En F. J. González (Ed.), Barbarie y civilización (pp. 17-32). Cádiz, España: Servicio de Publicaciones de la Universidad de Cádiz.

Chesterfield, L. (1852). Cartas Completas a su hijo Felipe Stanhope, Havre. París, Francia: Imprenta de Alfonso Lemale.

Cicerón. (1948). Los oficios. En M. Menéndez Pelayo (Ed.), Obras completas de Marco Tulio Cicerón, Vol. IV (pp. 1-213). Madrid, España: Librería y Casa Editorial Hernando.

Cicerón. (1948). De los deberes. México: UNAM.

Corbin, A. (2005). Introducción. En J.J. Courtine, A. Corbin, G. Vigarello (Eds.), Historia del cuerpo. Vol. 2: De la Revolución francesa a la Gran guerra (pp. 15-22). Madrid, España: Taurus.

De Ramón, A. (2011). Santiago de Chile (1541-1991): historia de una sociedad urbana. Santiago, Chile: Catalonia.

Druille, P. (2013). Clemente de Alejandría y las costumbres sociales en el marco apologético del Pedagogo. Bahía Blanca, Argentina: Universidad Nacional del Sur.

Elias, N. (1997). El proceso de civilización. Investigaciones sociogenéticas y sicogenéticas. Colombia: Fce. 
Erasmo, D. (2006). De la urbanidad en las maneras de los niños. Edición bilingüe con traducción y notas de Agustín García Calvo. Edición y comentario de Julia Varela. Madrid, España: Cide.

Erasmo, D. y Arroyal, L. (1797). Los Dísticos de Catón con escolios de Erasmo, traducidos y ampliados por don León de Arroyal. Madrid, España: Oficina de don Gerónimo Ortega.

Foucault, M. (2003). Tecnologías del yo y otros textos afines. Barcelona, España: Paidós.

García Romero, F. (1999). Introducción traducción y notas. En Menandro (Ed.), Sentencias. Madrid, España: Gredos.

Gómez Robledo, A. (1948). Introducción, traducción y notas. En Cicerón, De los deberes. México: UNAM.

Góngora, M. (1980). El rasgo utópico en el pensamiento de Juan Egaña. En Estudios de historia de las Ideas y de historia social (pp. 207-230). Santiago: Ediciones Universitarias de Valparaíso.

Hadot, P. (2006). Ejercicios espirituales y filosofía antigua. Madrid, España: Siruela.

Hayes, G.P. (1939). Cicero’ Humanism Today. The Classical Journal, 34(5), 283-290.

Henriquez, L. M. y Hugand, C. (1795). Principes de civilité républicaine, dédiés à l'enfance et à la jeunesse, sous les auspices de J.J. Rousseau; présenté à la Convention Nationale. A Paris: chez Hugand.

Inglebert, H. (2014). La civilisation romaine. Paris, Francia: Nouvelle Clio. 
Jenofonte. (1987). Ciropedia. Madrid, España: Gredos.

Langford, P. (1997). British Politeness and the Progress of Western Manners: An Eighteenth-Century Enigma. Transactions of the Royal Historical Society, 7, 53-72. doi: $10.2307 / 3679270$

Larrazábal, F. (1890). Método para la educación de un joven según Bolívar. En Cartas completas de Lord Chesterfield (t. I, pp. XV-XVI). París, Francia: Librería de Ch. Bouret.

Laspalas, J. (1998). Los códigos sociales de conducta como tema historiográfico. En Memoria y civilización, 1, (pp. 199-208). Navarra, España: Servicio de Publicaciones de la Universidad de Navarra. Recuperado de http://hdl.handle.net/10171/8934

Marrou, H.I. (1985). Historia de la educación en la antigüedad. Madrid, España: Akal.

Menandro. (1999). Sentencias. Madrid, España: Gredos.

Monsalve, M., Egaña, M.L. (2006). Civilizar y moralizar en la escuela primaria popular. En R. Sagredo; C. Gazmuri (Eds.), Historia de la vida privada en Chile: el Chile Moderno 1840 A 1925 (pp. 119-137). Santiago, Chile: Taurus.

Paternoster, A. (2004). Decorum and Indecorum in the "Seconda redazione" of Baldassare Castiglione's "Libro del Cortegiano". The Modern Language Review, 99(3), 622634. doi: $10.2307 / 3738991$

Peña, C. (6 de mayo de 2018). La epidemia del acoso sexual. El Mercurio, Cuerpo D, p. 7. 
Quadrini, U. (1989). Concepto de “Humanitas” en Cicerón. En N. Cruz, G. Grammatico, X. Ponce de León (Eds.), Encuentro Internacional Paideia, Humanitas y sus Proyecciones (pp. 161-170). Santiago, Chile: Universidad Metropolitana de Ciencias de la Educación.

Ramage, E.S. (1960). Early roman urbanity. The American Journal of Philology, 81(1), 6572.

Revel, J. (1989). Los usos de la civilidad. En Ph. Ariès y G. Duby (Eds.), Historia de la vida privada (tomo III, pp. 169-210). Madrid, España: Taurus.

Riesco, M. (1969). Instrucciones a su amado hijo Miguel. Santiago, Chile: Inostroza.

Roldán Vera, E. (2003). The British Book Trade and Spanish American Independence. Education and Knowledge Transmission in Transcontinental perspective. Aldershot, Inglaterra: Ashgate.

Rouvillois, F. (2008). Historia de la cortesía: de 1789 a nuestros días. Buenos Aires, Argentina: Claridad.

Ruiz García, E. (2007). Introducción traducción y notas. En Teofrasto, Caracteres (pp. 943). Madrid, España: Gredos.

Salas, M. de. (1910). Escritos de Don Manuel de Salas. Santiago, Chile: Cervantes.

Sanguinetti, J.J. (2000). La antropología educativa de Clemente alejandrino. El giro del paganismo al cristianismo. Pamplona, España: Eunsa. 
Sherman, N. (2005). Of manners and morals. British Journal of Educational Studies, 53(3), 272-289. Recuperado de https://onlinelibrary.wiley.com/doi/epdf/10.1111/j.14678527.2005.00295.x

Silva Vargas, F. (2013). El gobierno de Freire. En F. Silva V. y J. E. Vargas (Eds.), Historia de la República de Chile: (1808-1826). Volumen 1: El fin de la Monarquía y los orígenes de la República: (1808-1826) (pp. 545-584). Santiago, Chile: ZigZag.

Soaje de Elías, R. (2012a). La influencia del De oficiis de Cicerón en la historia de la urbanidad: el caso del manual de Carreño (1853). Boletín de la Academia Chilena de la Historia, LXXVIII(121), 201-212.

Soaje de Elías, R. (2012b). Estudio de los textos escolares de Historia y Ciencias Sociales chilenos entre 2000 y 2010. Educación y Educadores, 15(1), 23-41. Recuperado de http://www.scielo.org.co/pdf/eded/v15n1/v15n1a03.pdf

Soaje de Elías, R. (2014). Vestigios de latinidad clásica en reglas monásticas visigodas. Scripta Mediaevalia, 7(1), 63-80. Recuperado de http://bdigital.uncu.edu.ar/objetos_digitales/5818/scripta-m-004soajedeelias.pdf

Soaje de Elías, R. (2015). De Marco Tulio Cicerón a Manuel Antonio Carreño: un estudio sobre los ideales de vida de las élites en tres momentos de la Historia. Atenea, 511(I), 189-205. Recuperado de https://scielo.conicyt.cl/pdf/atenea/n511/art_10.pdf

Teofrasto. (2007). Caracteres. Barcelona, España: Gredos. 
Toro Blanco, P. (2012). Dimensiones de la confección de una juventud virtuosa: manuales de urbanidad en Chile (c.1840-c.1900). Universum, 27(1), 191-205. Recuperado de https://scielo.conicyt.cl/pdf/universum/v27n1/art_10.pdf

Vegas Sansalvador, A. (2006). Introducción, traducción y notas. En Jenofonte (Ed.), Ciropedia (pp. 7-66). Madrid, España: Gredos.

Villalobos, S. (2006). Origen y ascenso de la burguesía chilena. Santiago, Chile: Universitaria. 